\title{
Dobutamine Alters the Pharmacokinetic and Pharmacodynamic Behavior of Esmolol
}

\author{
Günther Krumpl ${ }^{1}$, Ivan Ulč ${ }^{2}$, Michaela Trebs ${ }^{3}$, Juri Hodisch ${ }^{4}$, Pavla Kadlecová ${ }^{5}$, Bernhard Husch ${ }^{6}$ \\ 1. Pharmacology, MRN Medical Research Network, Vienna, AUT 2. Pharmacology, Center for Pharmacology and \\ Analysis (CEPHA) s.r.o, Plzeň, CZE 3. Operational Business Development, AOP Orphan Pharmaceuticals AG, Vienna, \\ AUT 4. Drug Safety, AOP Orphan Pharmaceuticals AG, VIenna, AUT 5. Biostatistics, Advanced Drug Development \\ Services (ADDS) s.r.o, Brno, CZE 6. Research and Development, AOP Orphan Pharmaceuticals AG, Vienna, AUT
}

Corresponding author: Günther Krumpl, g.krumpl@medresnet.com

\section{Abstract \\ Background and objective}

This study involved an investigation into the pharmacokinetic and pharmacodynamic behavior of esmolol in the presence of dobutamine in healthy subjects of European ancestry.

\section{Methods}

We conducted a single-center, prospective randomized study of 16 healthy subjects with each receiving an infusion of dobutamine sufficient to increase heart rate (HR) by 30 beats per minute (bpm) followed by a 60 minute infusion of $50 \mu \mathrm{g} / \mathrm{kg} / \mathrm{min}$ esmolol. Pharmacokinetics, HR, and blood pressure were evaluated for 180 minutes.

\section{Results}

In the presence of dobutamine, esmolol elimination was substantially faster than without dobutamine, Esmolol infusion reduced dobutamine-induced elevation of HR reversibly whereas the dobutamine-induced systolic blood pressure (SBP) reduction did not recover after the termination of the esmolol infusion. No serious adverse events (AEs) were observed.

\section{Conclusions}

The accelerated elimination of esmolol was likely due to higher cleavage through tissue esterases induced by dobutamine-induced increased tissue passage cycles per time unit. The HR effect was characteristic of a beta-blocker, whereas the blood pressure effect was likely due to a mechanism other than direct betablockade. HR remained elevated after the infusion of esmolol and dobutamine, most likely due to persistent blood pressure reduction.

Review began $11 / 20 / 2020$ Review ended 12/16/2020 Published 12/22/2020

\section{○ Copyright 2020}

Krumpl et al. This is an open access article distributed under the terms of the Creative Commons Attribution License CC-BY 4.0., which permits unrestricted use, distribution, and reproduction in any medium, provided the original author and source are credited.
Categories: Cardiology

Keywords: cardioselective $\beta$-blocker, esmolol, dobutamine, pharmacokinetics, pharmacodynamics

\section{Introduction}

$\beta$-Adrenoceptor antagonists are effective regulators of heart rate (HR) in cases of sinus and supraventricular and ventricular tachycardia. Esmolol is an ultrashort-acting $\beta_{1}$-adrenoceptor antagonist for parenteral use with a high cardioselectivity $\left(K_{i} \beta_{1} / K_{i} \beta_{2}=34\right)$ [1]. It inhibits the positive chronotropic effects of the catecholamines adrenaline and noradrenaline on the heart, where $\beta_{1}$-receptors are predominantly located. In addition, esmolol also acts as an inhibitor of sodium ( $\mathrm{Na}$ ) and calcium ( $\mathrm{Ca}$ ) channels and blocks potassium (K) channels, which is thought to be the reason for its negative inotropic effect [2-5]. Its antiarrhythmic and anti-ischemic effects are thought to be due to the reduction of the sympathetic drive, which results in HR reduction, decrease in spontaneous firing of ectopic pacemakers, as well as slowing down of the electrical conduction of the atrioventricular (AV) node, and the increase in its refractory period. Also, exposure to esmolol amplifies the re-expression of $\beta$-receptors [6], which contributes to the drug tolerance effect seen during long-term esmolol infusion $[7,8]$.

Esmolol is a well-studied drug exhibiting typical $\beta$-blocker hemodynamic and electrophysiologic effects $[9,10]$. It is much more selective than other available intravenous (IV) $\beta$-blockers such as metoprolol [9]. With a reported in vivo half-life of nine minutes [11], esmolol is used for the rapid control of the ventricular rate in emergencies and in patients with perioperative tachycardic arrhythmias, tachycardia, and/or hypertension. In addition, it has been studied for treatment or prophylaxis of relative or absolute tachycardias in the perioperative phase with positive [12] or less positive [7,13,14] results. Further studies have been undertaken in unstable angina and acute myocardial infarction [15]. 
According to its summary of product characteristics (SPC) (see prescribing information for Brevibloc: $\mathrm{http} / /$ /brevibloc.com), the IV dosage schedule of esmolol is not particularly convenient and makes appropriate dosage administration cumbersome. Especially, different dose recommendations for different settings and the complicated staircase titration of 500 and $50 \mu \mathrm{g} / \mathrm{kg} / \mathrm{min}$ are prone to confuse the users.

Across the dosage range used in the clinical setting, steady-state blood concentrations of esmolol increase linearly, and elimination kinetics is reported to be not dose-dependent $[11,16]$. Esmolol is metabolized by esterases into an acid metabolite and methanol $[1,17]$. Since the half-life of esmolol is much longer in plasma than in whole blood, it has been assumed that these esterases are located in red blood cells [18]. However, in vitro studies have shown that the half-life of esmolol in human whole blood varies between 19.6 and 27.2 minutes at $37^{\circ} \mathrm{C}[19]$. Based on the fact that these in vitro values are still higher than the in vivo half-life of nine minutes observed in humans, we and others [20] assume that esmolol is to a higher extent metabolized by extravascular enzymes, as implied by its higher volume of distribution of around $31 / \mathrm{kg}$.

Dobutamine is a $\beta$-adrenoceptor agonist (predominantly $\beta_{1}$ ) with an inotropic effect. This sympathomimetic drug is commonly used as a cardiac stimulant in the treatment of heart failure and cardiogenic shock. It is also used in cardiac stress testing to help identify coronary artery disease, as an alternative to physical exercise in patients who cannot perform routine workouts in a satisfactory manner [21]. Because of its short half-life, dobutamine is administered as a continuous IV infusion.

In our prospective cross-over study in healthy Caucasian volunteers, we investigated the pharmacokinetic and pharmacodynamic characteristics of a permanent infusion of esmolol or landiolol during dobutamine challenge. We describe for the first time the pharmacodynamic and pharmacokinetic behavior of esmolol at the lowest recommended standard dose $(50 \mu \mathrm{g} / \mathrm{kg} / \mathrm{min})$ during dobutamine challenge; the results obtained with landiolol are presented separately [22].

\section{Materials And Methods \\ Materials}

Esmolol hydrochloride infusion solution (Brevibloc ${ }^{\circledR} 2,500 \mathrm{mg}$ esmolol/250 ml) was obtained from Baxter Vertriebs $\mathrm{GmbH}$ (Vienna, Austria). Dobutamine (Admeda 250 solution for infusion, $50 \mathrm{ml}$; concentration: 5 $\mathrm{mg} / \mathrm{ml}$; Admeda Arzneimittel $\mathrm{GmbH}$, Nienwohld, Germany) was diluted to $1 \mathrm{mg} / \mathrm{ml}$ with sterile isotonic saline prior to use.

\section{Study approval}

We performed a prospective single-center, prospective, double-blinded, randomized study with two crossover periods in compliance with the respective study protocol, the Declaration of Helsinki, Good Clinical Practice (GCP) and Good Laboratory Practice (GLP) guidelines, as well as other applicable international and national regulatory requirements and local laws after obtaining approval of the study protocol by the Ethics Committee. The study was registered at EudraCT (2010-023311-34). All study participants gave written informed consent before the conduct of the study-related procedures.

\section{Study population}

Sixteen healthy volunteers [as determined by medical history, physical examination, electrocardiogram (ECG), 2D-echocardiography, hematology, coagulation, clinical chemistry, serology, urinalysis, and testing for drug abuse at the screening] of European ancestry were recruited for the study. Inclusion criteria were as follows: age of 18-45 years (inclusive), a body-mass index (BMI) of $18.5-30.0 \mathrm{~kg} / \mathrm{m}^{2}$ (inclusive), nonsmoking, ex-smoking (completely stopped smoking for at least three months) or mild smoking (nine cigarettes or less per day). Exclusion criteria were, among others, a history or presence of clinically relevant cardiovascular, renal, hepatic, ophthalmic, pulmonary, neurological, metabolic, hematological, gastrointestinal, endocrine, immunological, psychiatric, or skin diseases, hypersensitivity to landiolol, esmolol, dobutamine, or related drugs, as well as pregnancy and/or breast-feeding. Individuals with inappropriate vascular anatomy (small, badly visible, or invisible veins) were also excluded.

\section{Study conduct}

Our prospective, double-blinded, randomized, two-period, two-treatment crossover study aimed at comparing the short-term pharmacokinetics, pharmacodynamics, and tolerability of landiolol with that of esmolol in the continuous presence of the adrenergic stimulant dobutamine in healthy volunteers; it was conducted between March and December 2011 at the Center for Pharmacology and Analysis (CEPHA s.r.o.), Plzeň, Czech Republic. Participants were assigned to one of two treatment sequences (landiolol/esmolol or esmolol/landiolol) using a predefined 1:1 randomization scheme. The duration of the treatment periods was two days each, with confinement from at least 11 hours before and until at least eight hours after the end of study drug administration, and a washout phase of two days minimum between periods. The end-of-study examination was performed within 72 hours after the end of infusion. 
Three indwelling catheters were placed into the cubital veins of each subject in each period. One catheter was used for dobutamine infusion and the other at the same arm for study drug infusion. Blood sampling was performed from the third catheter on the arm contralateral to the study drug administration site. Drug administration and sampling sites were switched between periods. Study subjects were required to maintain bed rest and supine position for safety reasons from the start of dobutamine infusion until two hours after the end of the study drug administration.

Dobutamine infusion was initiated at $10 \mu \mathrm{g} / \mathrm{kg} / \mathrm{min}$ for 10 minutes and incremented by $5 \mu \mathrm{g} / \mathrm{kg} / \mathrm{min}$ every 10 minutes until the targeted HR increase of at least 30 beats per minute (bpm) above baseline or a maximum dose of $30 \mu \mathrm{g} / \mathrm{kg} / \mathrm{min}$ was reached. Once the target HR was established, dobutamine administration was continued at an unchanged rate for another 20 minutes before esmolol (dose: $50 \mu \mathrm{g} / \mathrm{kg} / \mathrm{min}$ ) or landiolol (10 $\mu \mathrm{g} / \mathrm{kg} / \mathrm{min}$ ) was administered for 60 minutes. Dobutamine infusion was continued at an unchanged rate during and after $\beta$-blocker infusion until the HR had returned to a maximum value or to the value before $\beta$ blocker infusion or until 60 minutes after the end of the $\beta$-blocker infusion, whichever occurred first. ECG was monitored continuously from 10 minutes before initiation of dobutamine infusion until at least 120 minutes after the end of $\beta$-blocker infusion. ECG parameters (PQ, QRS, QT) were checked throughout at regular intervals.

\section{Measurements}

Blood samples were collected at time 0 (before the start of $\beta$-blocker infusion), and at 2, 4, 6, 8, 12, 16, 20, $28,36,44,60$ (end of infusion), 62, 64, 66, 68, 72, 76, 80, 88, 96, 104, 120 minutes, and 3, 5, 7, and 9 hours after the start of the infusion. HR values (derived from the signal of the bedside ECG monitor) were recorded at the time points for blood sampling and at 15-minute intervals thereafter until 180 minutes after the start of $\beta$-blocker infusion. Blood pressure [systolic blood pressure (SBP) and diastolic blood pressure (DBP), measured by the cuff method on the arm used for blood sampling] values were recorded at the start of dobutamine infusion, at 2, 4, 6, and 10 minutes of each dobutamine dose, at 2, 4, 6, 10, 15 and 20 minutes of the maintenance dobutamine dose, and at the start (0) of and at 4, 8, 16, 28, 44, and 60 minutes during study drug infusion. Further recordings were taken $64,68,76,88,104,120,135,150,165$, and 180 minutes after the start of $\beta$-blocker administration.

\section{Assessment of tolerability and safety}

Local tolerability was assessed at the start and at the end of $\beta$-blocker infusion, and two hours after the end of infusion as described earlier [23]. For the assessment of safety and tolerability, clinically relevant abnormalities in physical examination, vital signs, ECG, laboratory parameters, as well as local tolerability results and adverse events (AEs) were taken into account.

\section{Analytical procedure}

Concentrations of esmolol and its metabolite EM in supernatants of ethanol-precipitated whole blood were quantitated using a validated high-performance liquid chromatography-tandem mass spectrometry (HPLCMS/MS) method as described earlier [8]. The lower and upper limits of quantitation with this method were 1 $\mathrm{ng} / \mathrm{ml}$ and $550 \mathrm{ng} / \mathrm{ml}$, respectively for esmolol, and $55 \mathrm{ng} / \mathrm{ml}$ and $27.8 \mu \mathrm{g} / \mathrm{ml}$, respectively for EM. Intermediate precision (RSD) across the range of quantitation was $<8 \%$ and $<9 \%$ for esmolol and EM, respectively. Accuracy across the range of quantitation was between $93.9 \%$ and $107 \%$ for esmolol and $94.2 \%$ and $105.9 \%$ for EM. Stability of ethanol-precipitated whole blood samples has been shown for 23 hours at bench-top temperature, for 168 hours under auto-sampler conditions $\left(5^{\circ} \mathrm{C}\right)$, and for 38 weeks when stored at $\leqslant 70{ }^{\circ} \mathrm{C}$.

\section{Pharmacokinetic analysis}

Standard pharmacokinetic parameters for esmolol and its metabolite were estimated using noncompartmental as well as one- and two-compartmental models with the validated software package Phoenix ${ }^{\mathrm{TM}}$ WinNonlin ${ }^{\circledR}$ version 6.1 (Pharsight Corp., St. Louis, MO).

\section{Pharmacodynamic analysis}

Time courses of the pharmacodynamic variables were evaluated in terms of absolute values and changes from baseline on an individual basis and by using descriptive statistics for each data point.

\section{Statistical analysis}

Statistical analyses were performed using the software package SAS version 9.2 (SAS Institute Inc., Cary, NC).

\section{Results}

\section{Study population}




\section{Cureus}

The baseline demographic characteristics of the study populations are summarized in Table 1 . No substantial differences were notable between the groups.

\begin{tabular}{|c|c|c|c|}
\hline Demographic variable & Inclusion criterion & Esmolol + dobutamine $(n=16)$ & Esmolol long-term $(n=14)[8]$ \\
\hline Ethnicity & Caucasian White & Caucasian White & Caucasian White \\
\hline Gender & Both & & \\
\hline Female, n (\%) & & $8(50.0)$ & $7(50.0)$ \\
\hline Male, n (\%) & & $8(50.0)$ & $7(50.0)$ \\
\hline Age (years; mean \pm SD) & $18-45$ & $33.1 \pm 8.2$ & $34.4 \pm 8.9$ \\
\hline Weight (kg; mean \pm SD) & $50-90$ & $15.9 \pm 8.2$ & $73.6 \pm 8.7$ \\
\hline Height (cm; mean \pm SD) & - & $176.9 \pm 7.0$ & $1 / 3.1 \pm 8.5$ \\
\hline $\mathrm{BMI}\left(\mathrm{kg} / \mathrm{m}^{2} ;\right.$ mean $\left.\pm \mathrm{SD}\right)$ & $18.5-30$ & $24.2 \pm 1.8$ & $24.6 \pm 2.4$ \\
\hline Smoking habit & $\begin{array}{l}\leq 9 \text { clgarettes or } \leq 2 \text { clgars/pipes per } \\
\text { day }\end{array}$ & & \\
\hline Non-smoker, n (\%) & & $12(75.0)$ & $11(78.6)$ \\
\hline Mild smoker, n (\%) & & $4(25.0)$ & $3(21.4)$ \\
\hline
\end{tabular}

TABLE 1: Baseline demographic characteristics of study populations

SD: standard deviation; BMI: body mass index

\section{Maintenance dobutamine dose}

The mean dobutamine maintenance dose of $16.6 \mu \mathrm{g} / \mathrm{kg} / \mathrm{min}$ led to a median HR increase by $43 \mathrm{bpm}$.

\section{Pharmacokinetics}

Figure 1 shows the time courses of the blood concentrations of esmolol in the dobutamine group ( $\mathrm{n}=16)$ and 12 subjects in another study that received the same esmolol dose $(50 \mu \mathrm{g} / \mathrm{kg} / \mathrm{min})$ without dobutamine for two hours followed by infusion with higher dosages of esmolol (100 and $200 \mu \mathrm{g} / \mathrm{kg} / \mathrm{min}$ ) for up to 24 hours [8]. For this reason, the elimination phase under comparable conditions is not available.

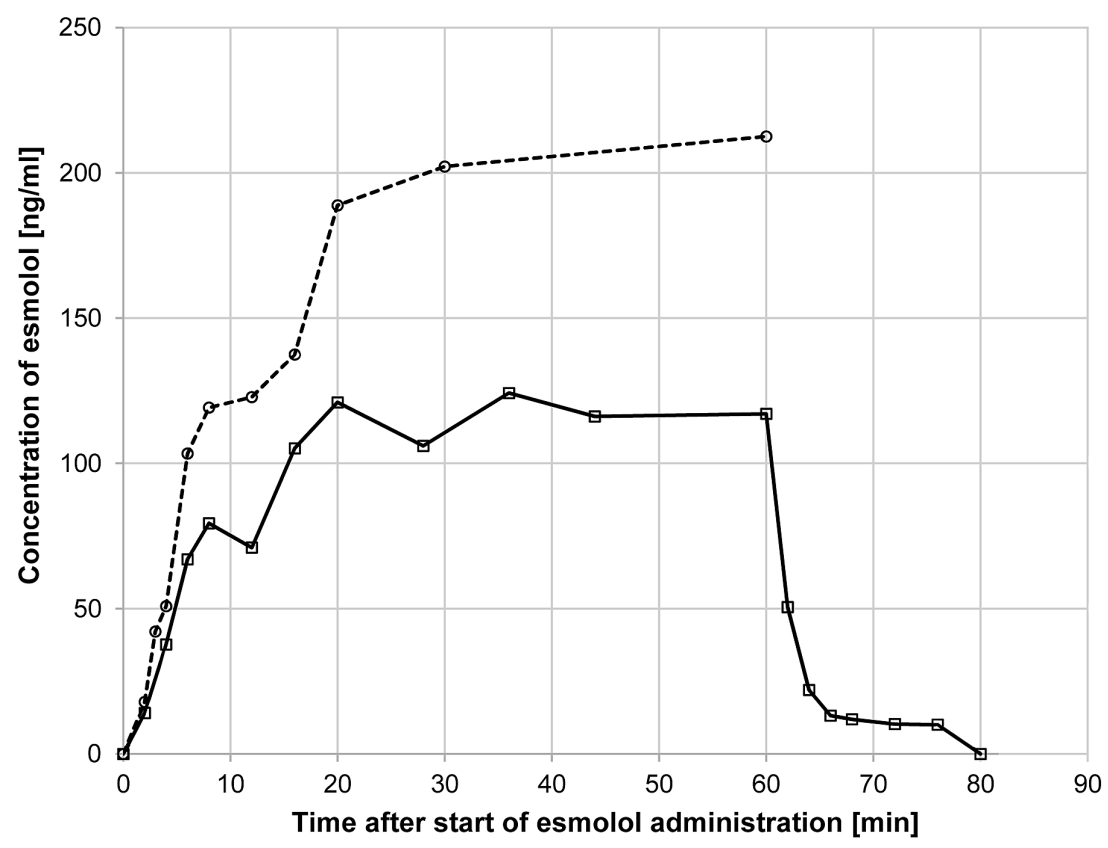




\section{Cureus}

FIGURE 1: Time course of esmolol concentrations in whole blood in the presence and absence of dobutamine

Open squares and solid line: infusion of esmolol ( $50 \mu \mathrm{g} / \mathrm{kg} / \mathrm{min})$ on top of continuous dobutamine infusion; open circles and broken line: infusion of esmolol $(50 \mu \mathrm{g} / \mathrm{kg} / \mathrm{min})$ only [8]. Please note that the elimination phase is lacking for the esmolol-only experiment, because infusion was continued at higher doses for an additional 23 hours

The curve obtained with esmolol infusion in the continuous presence of dobutamine differs substantially from the curve obtained during infusion of esmolol only. The latter shows a later steady-state plateau, whereas, under dobutamine, esmolol achieves an earlier steady-state, a lower $\mathrm{c}_{\max }$, and a lower area under the curve (AUC). Esmolol concentrations decreased rapidly after the termination of infusion.

Table 2 summarizes the pharmacokinetic parameters obtained for esmolol when administered in the presence or absence of a continuous dobutamine challenge.

\begin{tabular}{|c|c|c|c|c|}
\hline Parameter & Statistic & $\begin{array}{l}\text { Esmolol }(50 \mu \mathrm{g} / \mathrm{kg} / \mathrm{min}) \text { for } 60 \\
\text { minutes in the presence of } \\
\text { dobutamine }(n=16)\end{array}$ & $\begin{array}{l}\text { Esmolol }(50 \mu \mathrm{g} / \mathrm{kg} / \mathrm{min}) \text { for } 60 \\
\text { minutes in the absence of } \\
\text { dobutamine }(n=14)^{\star}[8]\end{array}$ & $\begin{array}{l}\text { Esmolol }(200 \mu \mathrm{g} / \mathrm{kg} / \mathrm{min}) \text { for } 20 \\
\text { hours in the absence of } \\
\text { dobutamine }(\mathrm{n}=14)^{\star}[8]\end{array}$ \\
\hline \multirow[t]{2}{*}{$\begin{array}{l}\mathrm{C}_{\max } \\
(\mathrm{ng} / \mathrm{ml})\end{array}$} & $\begin{array}{l}\text { Geo } \\
\text { mean } \\
(\mathrm{SD})\end{array}$ & 151 (1.49) & 250 (1.41) & 1,290 (1.32) \\
\hline & $95 \% \mathrm{Cl}$ & $122-186$ & 205-305 & $1,100-1,520$ \\
\hline \multirow[t]{2}{*}{$t_{\max }(\min )$} & Median & 20 & 20 & \\
\hline & Range & $6.0-44$ & $6.0-60$ & \\
\hline \multirow[t]{2}{*}{$t_{\text {lag }}(\min )$} & Median & 4.0 & 3.0 & NA \\
\hline & Range & $2.0-12.0$ & $2.0-6.0$ & NA \\
\hline \multirow[t]{2}{*}{$\begin{array}{l}\mathrm{C}_{\mathrm{sS}} \\
(\mathrm{ng} / \mathrm{ml})^{\S}\end{array}$} & $\begin{array}{l}\text { Geo } \\
\text { mean } \\
(\mathrm{SD})\end{array}$ & 115 (1.44) & 203 (1.31) & 764 (1.48) \\
\hline & $95 \% \mathrm{Cl}$ & 94.9-140 & $174-237$ & 609-958 \\
\hline \multirow[t]{2}{*}{$\begin{array}{l}\mathrm{AUC}_{0-1} \mathrm{~h} \\
\text { (ng.min/ml) }\end{array}$} & $\begin{array}{l}\text { Geo } \\
\text { mean } \\
(\mathrm{SD})\end{array}$ & 6,260 (1.43) & $10,700(1.40)$ & $51,500(1.42)$ \\
\hline & $95 \% \mathrm{Cl}$ & $5,180-7,560$ & $8,830-13,000$ & $42,100-63,100$ \\
\hline \multirow[t]{2}{*}{$\begin{array}{l}\mathrm{AUC}_{0-\mathrm{t}} \\
\text { (ng.min/ml) }\end{array}$} & $\begin{array}{l}\text { Geo } \\
\text { mean } \\
(\mathrm{SD})\end{array}$ & $6,540(1.43)$ & & \\
\hline & $95 \% \mathrm{Cl}$ & $5,400-7,920$ & & \\
\hline \multirow[t]{2}{*}{$\begin{array}{l}\mathrm{AUC}_{0-\infty} \\
\text { (ng.min/ml) }\end{array}$} & $\begin{array}{l}\text { Geo } \\
\text { mean } \\
(\mathrm{SD})\end{array}$ & $6,660(1.44)^{\dagger}$ & & \\
\hline & $95 \% \mathrm{Cl}$ & $5,400-8,160^{\dagger}$ & & \\
\hline \multirow[t]{2}{*}{$t_{1 / 2}(\min )$} & $\begin{array}{l}\text { Geo } \\
\text { mean } \\
(\mathrm{SD})\end{array}$ & $2.85(1.92)^{\dagger}$ & & $7.13(1.47)$ \\
\hline & $95 \% \mathrm{Cl}$ & $1.98-4.09^{\dagger}$ & & $5.71-8.92$ \\
\hline$\lambda_{z}(1 / \min )$ & $\begin{array}{l}\text { Geo } \\
\text { mean } \\
(\mathrm{SD})\end{array}$ & $0.244(1.92)^{\dagger}$ & & 0.097 (1.47) \\
\hline
\end{tabular}




\section{Cureus}

\begin{tabular}{|c|c|c|c|c|}
\hline & $95 \% \mathrm{Cl}$ & $0.17-0.35^{\dagger}$ & & $0.078-0.121$ \\
\hline \multirow[t]{2}{*}{$\begin{array}{l}\text { CL } \\
\text { (ml/kg.min) }\end{array}$} & $\begin{array}{l}\text { Geo } \\
\text { mean } \\
\text { (SD) }\end{array}$ & $432(1.47)^{\dagger}$ & 243 (1.31) & $262(1.48)$ \\
\hline & $95 \% \mathrm{Cl}$ & $349-534^{\dagger}$ & 208-284 & $209-328$ \\
\hline \multirow[t]{2}{*}{$V_{D}(\mathrm{ml} / \mathrm{kg})$} & $\begin{array}{l}\text { Geo } \\
\text { mean } \\
\text { (SD) }\end{array}$ & $1,770(1.76)^{\dagger}$ & $2,500(1.57)$ & $2,690(1.67)$ \\
\hline & $95 \% \mathrm{Cl}$ & $1,300-2,430^{\dagger}$ & $1,930-3,260$ & $1,810-3,220$ \\
\hline
\end{tabular}

TABLE 2: Pharmacokinetic parameters (noncompartmental analysis) of esmolol in the presence and absence of dobutamine in healthy Caucasians

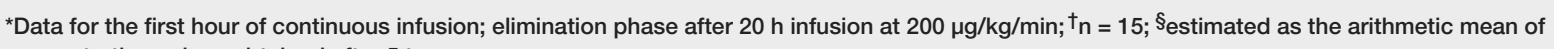
concentration values obtained after $5 \mathrm{t}_{1 / 2}$

$\mathrm{c}_{\text {max }}$ : maximum blood concentration; $\mathrm{t}_{\max }$ : time of maximum blood concentration; $\mathrm{c}_{\mathrm{ss}}$ : steady-state concentration; $A \mathrm{C}_{0-1} \mathrm{~h}$ : area under the blood concentration-time curve from $0 \mathrm{~h}$ until $1 \mathrm{~h} ; \mathrm{AUC}_{0-\mathrm{t}}$ : area under the blood concentration-time curve from $0 \mathrm{~h}$ to the last measurable concentration value; $\mathrm{AUC}_{0-\infty}$ : area under the blood concentration-time curve from $0 \mathrm{~h}$ to infinity; $\lambda_{2}$ : terminal elimination rate constant; $t_{1 / 2}:$ elimination half-life during the terminal phase; $t_{\text {lag }}$ : time until first measurable concentration; $C L$ : total clearance; $V_{D}$ : volume of distribution; $95 \% \mathrm{Cl}: 95 \%$ confidence interval; NA: not applicable; SD: standard deviation; geo mean: geometric mean

In the presence of dobutamine, the following parameters were obtained for esmolol: steady-state was reached at about 20 minutes, with a $\mathrm{c}_{\mathrm{ss}}$ value of $115 \mathrm{ng} / \mathrm{ml}$. The maximum blood concentration of esmolol $(151 \mathrm{ng} / \mathrm{ml})$ was observed after 20 minutes. After the discontinuation of administration, esmolol disappeared very fast from the bloodstream with a $\mathrm{t}_{1 / 2}$ of 2.9 minutes. The volume of distribution was $1,770 \mathrm{ml} / \mathrm{kg}$, and the total clearance was $432 \mathrm{ml} / \mathrm{kg}$.min. The corresponding values in the absence of dobutamine were $\mathrm{c}_{\mathrm{ss}}=$ $203 \mathrm{ng} / \mathrm{ml}, \mathrm{c}_{\max }=250 \mathrm{ng} / \mathrm{ml}, \mathrm{T}_{\max }=20$ minutes, $\mathrm{CL}=243 \mathrm{ml} / \mathrm{kg} \cdot \min$ and $\mathrm{V}_{\mathrm{D}}=2,500 \mathrm{ml} / \mathrm{kg}$, respectively. The elimination half-life (obtained after infusion for 24 hours) was 7.1 minutes. In the presence of dobutamine, $\mathrm{c}_{\mathrm{sS}}$ decreased by $53 \%, \mathrm{c}_{\max }$ by $40 \%, \mathrm{t}_{1 / 2}$ by $60 \%$, and AUC by $42 \%$ compared to the values obtained in the absence of dobutamine. The distribution volume decreased by $29 \%$ while total clearance was increased by $78 \%$. It is worth noting that the ratios of distribution volume and total clearance were not substantially different when compared to the values obtained with the administration of esmolol at 50 or $200 \mu \mathrm{gg} / \mathrm{kg} / \mathrm{min}$.

\section{Pharmacodynamics}

Figure 2 shows the time courses of HR, and SBP, and DBP (all values median). After the initial increase from 67.5 to $113 \mathrm{bpm}$ due to the administration of dobutamine, HR showed a precipitous decline (from 113 to 85 bpm within four minutes) in response to esmolol. The maximum reduction in HR was observed after $18.6 \pm$ 4.9 minutes. Between 16 minutes after the initiation of administration and the end of the administration, $\mathrm{HR}$ values were stable around $80 \mathrm{bpm}$. After the discontinuation of esmolol infusion, a pronounced rebound of HR occurred. The maximum median value of $111.5 \mathrm{bpm}$ was recorded six minutes after the discontinuation of esmolol; when evaluated on an individual basis, the peak occurred $8.6 \pm 2.3$ minutes after the discontinuation of esmolol (Figure 2, Table 3). 


\section{Cureus}

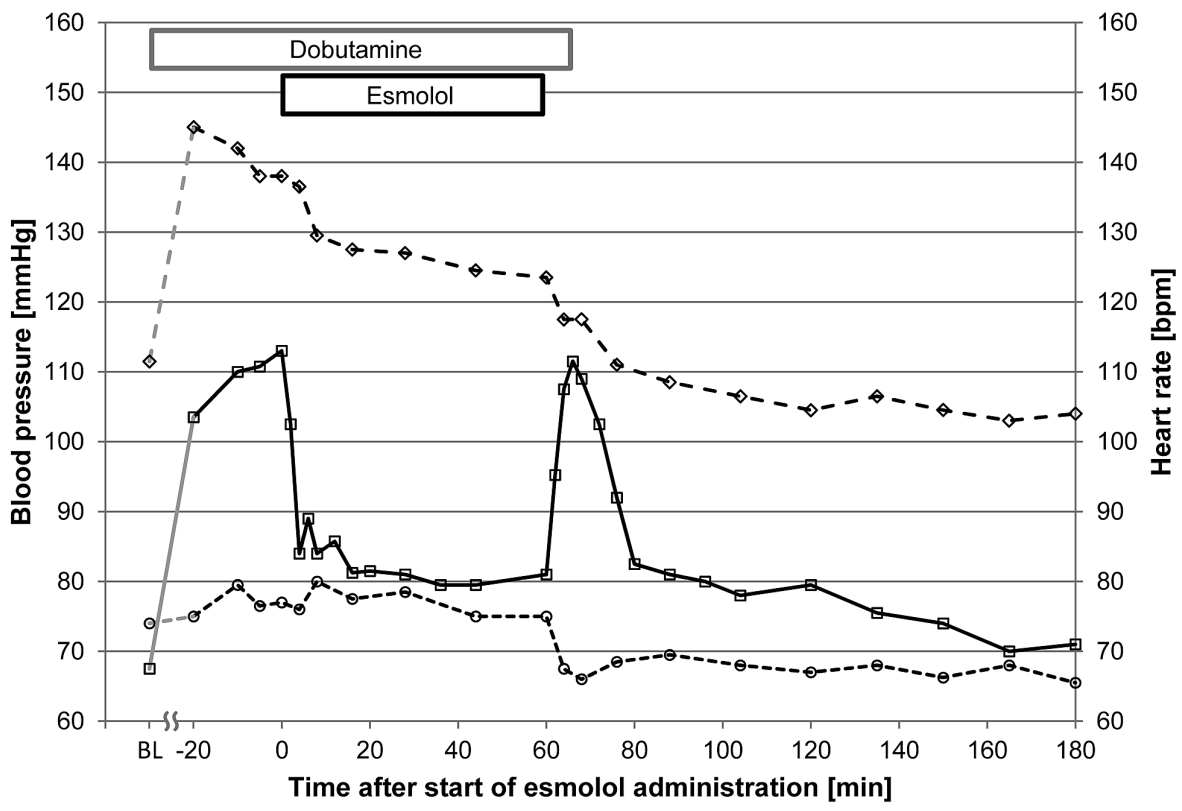

FIGURE 2: Time course of heart rate, and systolic and diastolic blood pressure

Open squares and solid line: heart rate; open diamonds and broken line: systolic blood pressure; open circles and dotted line: diastolic blood pressure

BL: baseline 


\section{Cureus}

\begin{tabular}{|c|c|c|c|}
\hline Time (minutes) & HR [IQR] (bpm) & SBP [IQR] (mmHg) & DBP [IQR] (mmHg) \\
\hline Baseline & $67.5[63.5,72.3]$ & $111.5[105.0,114.5]$ & $74.0[68.8,77.3]$ \\
\hline-20 & $103.5[95.0,112.3]$ & $145.0[121.0,153.5]$ & $75.0[69.5,85]$ \\
\hline-10 & $110.0[102.8,114.0]$ & $142.0[126.3,151.0]$ & $79.5[71.0,84.3]$ \\
\hline-5 & $110.8[104.8,115.8]$ & $138.0[119.0,149.3]$ & $76.5[71.3,83.0]$ \\
\hline 0 & $113.0[108.3,117.0]$ & $138.0[120.0,153.0]$ & $77.0[68.0,83.5]$ \\
\hline 2 & $102.5[91.8,106.9]$ & - & - \\
\hline 4 & $84.8[75.0,92.8]$ & $136.5[121.8,143.0]$ & $76.0[72.0,884.3]$ \\
\hline 6 & $89.0[73.5,93.3]$ & - & - \\
\hline 8 & $84.0[76.3,89.3]$ & $129.5[122.3,136.3]$ & $80.0[74.3,84.5]$ \\
\hline 12 & $85.8[74.1,88.5]$ & - & - \\
\hline 16 & $81.38[75.5,88.3]$ & $127.5[119.5,136.5]$ & $77.5[72.8,83.5]$ \\
\hline 20 & $81.5[73.1,85.3]$ & - & - \\
\hline 28 & $81.0[72.8,86.8]$ & $127.0[120.3,132.0]$ & $78.5[73.5,81.3]$ \\
\hline 36 & $79.5[73.5,85.6]$ & - & - \\
\hline 44 & $79.5[71.5,84.3]$ & $124.5[118.0,131.0]$ & $75.0[64.0,82.3]$ \\
\hline 60 & $81.0[73.3,83.3]$ & $124.5[116.9,128.3]$ & $75.0[68.8,83.3]$ \\
\hline 62 & $95.3[92.1,101.5]$ & - & - \\
\hline 64 & $10 / .5[101.0,110.1]$ & $117.5[108.3,126.3]$ & $67.5[63.0,73.8]$ \\
\hline 66 & $111.5[107.0,114.8]$ & - & - \\
\hline 68 & $109.0[105.0,113.8]$ & $117.5[106.8,127.5]$ & $66.0[62.8,76.5]$ \\
\hline 72 & $102.5[94.9,109.6]$ & - & - \\
\hline 76 & $92.0[85.0,103.3]$ & $111.0[106.8,124.3]$ & $68.5[59.8,76.5]$ \\
\hline 80 & $82.5[/ 7.8,94.0]$ & - & - \\
\hline 88 & $81.0[75.0,89.0]$ & $108.5[100.8,116.8]$ & $69.5[61.8,75.0]$ \\
\hline 96 & $80.0[75.1,88.5]$ & - & - \\
\hline 104 & $78.0[73.5,87.5]$ & $106.5[101.0,112.0]$ & $68.0[62.0,73.0]$ \\
\hline 120 & $79.5[71.5,85.0]$ & $104.5[98.5,108.3]$ & $67.0[58.3,75.0]$ \\
\hline 135 & $75.5[70.5,85.0]$ & $106.5[103.8,113.3]$ & $68.0[59.3,76.0]$ \\
\hline 150 & $74.0[69.0,81.0]$ & $104.5[101.5,107.3]$ & $66.3[59.8,72.3]$ \\
\hline 165 & $70.0[67.0,78.0]$ & $103.0[97.3,109.0]$ & $68.0[59.8,76.0]$ \\
\hline 180 & $71.0[67.5,80.3]$ & $104.0[95.30,107.3]$ & $65.5[55.8,75.3]$ \\
\hline
\end{tabular}

TABLE 3: Time courses of heart rate and systolic and diastolic blood pressure during and after infusion of esmolol for 60 minutes on top of continuous dobutamine infusion in healthy volunteers of European ancestry $(n=16)$

HR: heart rate; SBP: systolic blood pressure; DBP: diastolic blood pressure; IQR: interquartile range 
at -20 minutes, that is, at the beginning of the dobutamine stabilization/maintenance phase. From that time point on, the SBP values decreased irrespective of the presence or absence of dobutamine and/or esmolol until 60 minutes after the discontinuation of esmolol. There was a slight downward shift of the curve between zero and eight minutes by some $8.5 \mathrm{mmHg}$ in response to the initiation of esmolol administration, slightly delayed compared to the HR response. Afterward, there was a slight but continuous reduction of SBP values until the end of the esmolol infusion. When esmolol was discontinued, there was, in contrast to the HR increase, another downward shift in the curve by $7 \mathrm{mmHg}$ within four minutes. The reduction continued, and baseline values were reached at 16 minutes after discontinuation of esmolol. From that time point on, the decrease to a stable plateau until the end of the observation period at around $105 \mathrm{mmHg}$ was still 6 $\mathrm{mmHg}$.

DBP values also showed an unexpected time course, which was however different from the one seen with SBP. There was a slight increase during dobutamine titration, but apart from a single reduced value at four minutes, values were increased during esmolol administration compared to zero minute until 26 minutes. Thereafter, there was a slow reduction, and DBP returned to baseline values by 60 minutes. A marked notch (-9 mmHg within eight minutes) occurred in response to esmolol discontinuation followed by a slight recovery (coincident with the end of the HR rebound peak) to values around $67 \mathrm{mmHg}$, which were maintained until the end of the observation period.

\section{Safety and tolerability}

During the study period, 38 AEs occurred in 12 subjects; 20 AEs occurred before the administration of esmolol. Only one AE (fatigue after esmolol administration) was considered related to the study treatment. No serious AEs were observed.

\section{Discussion}

In this prospective study among healthy Caucasian volunteers, we evaluated the pharmacodynamic and pharmacokinetic profile of esmolol in the presence of a continuous dobutamine infusion and compared the results with those obtained in the absence of dobutamine.

\section{Pharmacokinetics}

Esmolol showed the expected pharmacokinetic behavior in the presence of dobutamine.

The geometric mean maximum concentrations of esmolol in blood reached $151 \mathrm{ng} / \mathrm{ml}$ at $\mathrm{t}_{\max }$ of 20 minutes (median; range: 6-44 minutes). While this is close to the mean steady-state concentration ( $\mathrm{c}_{\mathrm{ss}}$ ) of $164 \mathrm{ng} / \mathrm{ml}$ reported by Sum et al. at the same infusion rate [11], the $\mathrm{c}_{\mathrm{ss}}$ values obtained in our study $(115 \mathrm{ng} / \mathrm{ml})$ are substantially lower. The mean volume of distribution $\left(V_{D}\right)$ reported by Sum et al. $(2,140 \mathrm{ml} / \mathrm{kg})$ for the same dose [11] is halfway between our results obtained with and without dobutamine $(1,700$ and 2,500 $\mathrm{ml} / \mathrm{kg}$, respectively).

After the end of esmolol infusion, the drug disappeared rapidly from the blood with a half-life of 2.8 minutes [Geometric mean (geo mean); 95\% CI: 2.0-4.1 minutes]. This value was similar to the mean distribution halflife of 3.69 minutes at $50 \mu \mathrm{g} / \mathrm{kg} / \mathrm{min}$ reported by Sum et al. using a model-independent kinetic analysis [11]. It is worth noting that in the study by Sum et al., the distribution and elimination phases of esmolol could not be clearly resolved at infusion rates of 50 and $150 \mu \mathrm{g} / \mathrm{kg} / \mathrm{min}$ [11]. Distribution and elimination half-lives could therefore be calculated for the highest dose of $400 \mu \mathrm{g} / \mathrm{kg} / \mathrm{min}$ only, using the pharmacokinetic model developed by the authors, with respective values of 2.03 and $9.19 \mathrm{~min}$. This is in line with our observations that distribution and elimination occur simultaneously at the dose of $50 \mu \mathrm{g} / \mathrm{kg} / \mathrm{min}$, as seen in the majority of subjects.

Geometric mean total clearance of esmolol (432 ml/kg.min) was about 20\% higher than the value reported by Sum et al. for an infusion rate of $50 \mu \mathrm{g} / \mathrm{kg} / \mathrm{min}$ (363 $\pm 184 \mathrm{ml} / \mathrm{kg} . \mathrm{min})$ [11] and more than $50 \%$ higher compared to the ones we have assessed in a similar population using both 50 and $200 \mu \mathrm{g} / \mathrm{kg} / \mathrm{min}$ (Table 2). If esmolol is in fact metabolized predominantly by esterases found in the cytosol of red blood cells, as has been reported repeatedly, the higher esmolol clearance observed in our setting could be explained by higher esmolol cleavage in the erythrocytes and an increased extraction due to elevated liver passage.

Esmolol when studied in vitro shows a half-life of 60.4 minutes in red blood cell suspensions [18]. Plasma contribution to esmolol elimination is even lower since the in vitro half-life of esmolol in plasma is $>180$ minutes [18]. Given the in vivo half-life of nine minutes, the assumption that esmolol is metabolized by red blood cell esterases cannot be upheld, and it is more likely that esmolol is in fact metabolized predominantly by tissue esterases and to a far lesser extent by plasma and red cell esterases. There are several lines of evidence that support this hypothesis.

1. Marked differences in concentration between arterial and venous blood samples have been reported earlier, which indicates a substantial cleavage of esmolol during an arterio-venous passage [20,24]. It has 
2. A higher participation of elimination through the liver seems not plausible since the liver plays no role in esmolol elimination [25].

3. Our finding that the increase in HR and blood pressure, and, although not measured but described and obvious, also the associated increase in cardiac index leads to a reduction of passage times and increase of passage cycles per time unit. This speeded up the elimination of esmolol. Dobutamine does not necessarily increase the elimination of short-acting $\beta$-blockers, as landiolol showed no or only a minimal decrease in half-life when administered on top of dobutamine [22]. As landiolol has a substantially lower distribution volume than esmolol [8], this discrepancy can be explained easily. The in vitro half-life of landiolol in human blood is identical to the in vivo half-life [26], which indicates that landiolol is cleaved by blood esterases and does not depend on tissue esterases. In the case of esmolol, the discrepancy between the in vitro and the in vivo half-lives is however 27 to 9 minutes [19], that is, a factor of 3 . This indicates that about $66 \%$ of esmolol elimination does not occur in erythrocytes but in the tissue. An increase of tissue passage cycles per time unit will accordingly accelerate the elimination of esmolol substantially.

\section{Pharmacodynamics}

Dobutamine induced a substantial increase in HR from 67.5 to $113.0 \mathrm{bpm}$. In the presence of dobutamine, esmolol induced a rapid decrease in HR. We observed a clear inverse relationship between $\beta$-blocker concentration and the decrease in dobutamine-stimulated HR. Within four minutes of infusion start, esmolol concentrations in blood increased rapidly, and HR dropped as fast. Conversely, after the discontinuation of the $\beta$-blocker infusion, HR promptly returned to its initial (dobutamine-induced) high level. After dobutamine switch-off, the HR decreased but remained elevated when compared to the predobutamine levels. We suspect that the fast recovery of the HR is driven not only by the renewed betaadrenergic stimulation by dobutamine following esmolol elimination but also by a reflex phenomenon triggered by the reduced blood pressure and a rebound effect due to the pharmacochaperoning activity of esmolol [6] as observed in an earlier study [8].

Dobutamine likewise also induced an increase in SBP and - to a lesser degree - in DBP. Within eight minutes of the initiation of esmolol administration, there was a marked SBP reduction (by some $8 \mathrm{mmHg}$ ) followed by a continuous decrease by another $5 \mathrm{mmHg}$ during the 60-minute administration time. Of note, discontinuation of esmolol administration did not result in a recovery to pre-administration levels; on the contrary, there was a further marked decrease by some $7 \mathrm{mmHg}$ within a few minutes followed by a continuous reduction towards and below the baseline level over the next 20 minutes. The effect on DBP was marginal.

While a decrease in blood pressure is common with $\beta$-blocker administration, two observations deserve mention: first of all, the time constant of the effect on blood pressure is markedly different from the one on HR. While the major part of the effect on HR (about 80\%) was seen within four minutes, the effect on SBP was delayed (50\% of the effect within eight minutes, and another 50\% during the 60 -minute administration phase). The second - and more intriguing - observation is the fact that the blood pressure did not recover after the discontinuation of esmolol administration. A rapid onset of the bradycardic effect and a delayed but sustained blood pressure-lowering effect has been described earlier for esmolol [27]. Further factors for a $\beta$-receptor-independent blood pressure-lowering effect of esmolol come from the $\mathrm{Na}$, $\mathrm{Ca}$, and $\mathrm{K}$ channelblocking activities and the decrease in renin described for this drug [3-5,28].

In our case, one could speculate that dobutamine-induced receptor desensitization is involved in the nonrecovery of SBP, but this is ruled by the complete HR recovery after discontinuation of esmolol administration.

It should be noted that the HR remained elevated after both agents were switched off. This can be explained by a persistent blood pressure reduction, a post-esmolol phenomenon described before, that induces a sympathetic reflex [27,29]. Such a reflex might also trigger coronary spasms, which have been described after esmolol administration with the intent to speed up the termination of a dobutamine stress echo [30].

In summary, esmolol inhibits the positive chronotropic effect of dobutamine in a fast and, as expected and explainable by the short half-life, reversible fashion. The dobutamine-induced elevation of SBP was likewise reduced but not in a reversible fashion. Unexpectedly, dobutamine significantly speeds up the elimination of esmolol leading to a higher clearance and consequently lower blood levels and distribution volumes when compared to the elimination pattern in the absence of dobutamine.

\section{Conclusions}

In the presence of dobutamine, esmolol elimination is substantially faster than without dobutamine. This accelerated elimination can be explained by higher cleavage through tissue esterases induced by dobutamine-induced increased tissue passage cycles per time unit. Esmolol infusion reversibly reduces dobutamine-induced elevation of HR. In contrast, infusion of esmolol reduces the dobutamine-induced SBP 
without recovery after the termination of the esmolol infusion. HR remains elevated after esmolol and dobutamine most likely because of persistent blood pressure reduction.

\section{Additional Information \\ Disclosures}

Human subjects: Consent was obtained by all participants in this study. Institutional Review Board of CEPHA s.r.o. issued approval CPA 368-10. This study was approved by the Institutional Review Board of CEPHA s.r.o. Animal subjects: All authors have confirmed that this study did not involve animal subjects or tissue. Conflicts of interest: In compliance with the ICMJE uniform disclosure form, all authors declare the following: Payment/services info: All authors have declared that no financial support was received from any organization for the submitted work. Financial relationships: All authors have declared that they have no financial relationships at present or within the previous three years with any organizations that might have an interest in the submitted work. Other relationships: All authors have declared that there are no other relationships or activities that could appear to have influenced the submitted work.

\section{References}

1. Jahn P, Eckrich B, Schneidrowski B, Volz-Zang C, Schulte B, Mutschler E, Palm D: Beta 1-adrenoceptor subtype selective antagonism of esmolol and its major metabolite in vitro and in man. Investigations using tricresylphosphate as red blood cell carboxylesterase inhibitor. Arzneim-Forsch/Drug Res. 1995, 45:536-41.

2. Arlock P, Wohlfart B, Sjöberg T, Steen S: The negative inotropic effect of esmolol on isolated cardiac muscle . Scand Cardiovasc J. 2005, 39:250-4. 10.1080/14017430510035952

3. Deng CY, Lin SG, Zhang WC, et al.: Esmolol inhibits Na+ current in rat ventricular myocytes . Methods Find Exp Clin Pharmacol. 2006, 28:697-702. 10.1358/mf.2006.28.10.1037498

4. Fallouh HB, Bardswell SC, McLatchie LM, Shattock MJ, Chambers DJ, Kentish JC: Esmolol cardioplegia: the cellular mechanism of diastolic arrest. Cardiovasc Res. 2010, 87:552-60. 10.1093/cvr/cvq058

5. Shibata S, Okamoto Y, Endo S, Ono K: Direct effects of esmolol and landiolol on cardiac function, coronary vasoactivity, and ventricular electrophysiology in guinea-pig hearts. J Pharmacol Sci. 2012, 118:255-65. 10.1254/jphs.11202fp

6. Nasrollahi-Shirazi S, Sucic S, Yang Q, Freissmuth M, Nanoff C: Comparison of the $\beta$-adrenergic receptor antagonists landiolol and esmolol: receptor selectivity, partial agonism, and pharmacochaperoning actions. J Pharmacol Exp Ther. 2016, 359:73-81. 10.1124/jpet.116.232884

7. Harwood TN, Butterworth J, Prielipp RC, Royster RL, Hansen K, Plonk G, Dean R: The safety and effectiveness of esmolol in the perioperative period in patients undergoing abdominal aortic surgery. J Cardiothorac Vasc Anesth. 1999, 13:555-61. 10.1016/s1053-0770(99)90007-1

8. Krumpl G, Ulč I, Trebs M, Kadlecová P, Hodisch J, Maurer G, Husch B: Pharmacokinetics and pharmacodynamics of low-, intermediate-, and high-dose landiolol and esmolol during long-term infusion in healthy whites. J Cardiovasc Pharmacol. 2018, 71:137-46. 10.1097/FJC.0000000000000554

9. Garnock-Jones KP: Esmolol: a review of its use in the short-term treatment of tachyarrhythmias and the short-term control of tachycardia and hypertension. Drugs. 2012, 72:109-32. 10.2165/11208210-00000000000000

10. Wiest D: Esmolol. A review of its therapeutic efficacy and pharmacokinetic characteristics . Clin Pharmacokinet. 1995, 28:190-202. 10.2165/00003088-199528030-00002

11. Sum CY, Yacobi A, Kartzinel R, Stampfli H, Davis CS, Lai CM: Kinetics of esmolol, an ultra-short-acting beta blocker, and of its major metabolite. Clin Pharmacol Ther. 1983, 34:427-34. 10.1038/clpt.1983.193

12. Urban MK, Markowitz SM, Gordon MA, Urquhart BL, Kligfield P: Postoperative prophylactic administration of beta-adrenergic blockers in patients at risk for myocardial ischemia. Anesth Analg. 2000, 90:1257-61. 10.1097/00000539-200006000-00001

13. Kirshenbaum JM, Kloner RA, Antman EM, Braunwald E: Use of an ultra short-acting beta-blocker in patients with acute myocardial ischemia. Circulation. 1985, 72:873-80. 10.1161/01.cir.72.4.873

14. Balcetyte-Harris N, Tamis JE, Homel P, Menchavez E, Steinberg JS: Randomized study of early intravenous esmolol versus oral beta-blockers in preventing post-CABG atrial fibrillation in high risk patients identified by signal-averaged ECG: results of a pilot study. Ann Noninvasive Electrocardiol. 2002, 7:86-91. 10.1111/j.1542-474x.2002.tb00147.x

15. Er F, Dahlem KM, Nia AM, et al.: Randomized control of sympathetic drive with continuous intravenous esmolol in patients with acute ST-segment elevation myocardial infarction: the BEtA-Blocker Therapy in Acute Myocardial Infarction (BEAT-AMI) trial. JACC Cardiovasc Interv. 2016, 9:231-40. 10.1016/j.jcin.2015.10.035

16. Krumpl G, Ulc I, Trebs M, Kadlecová P, Hodisch J: Bolus application of landiolol and esmolol: comparison of the pharmacokinetic and pharmacodynamic profiles in a healthy Caucasian group. Eur J Clin Pharmacol. 2017, 73:417-28. 10.1007/s00228-016-2176-0

17. Volz-Zang C, Eckrich B, Jahn P, Schneidrowski B, Schulte B, Palm D: Esmolol, an ultrashort-acting, selective beta 1-adrenoceptor antagonist: pharmacodynamic and pharmacokinetic properties. Eur J Clin Pharmacol. 1994, 46:399-404. 10.1007/BF00191900

18. Quon CY, Stampfli HF: Biochemical properties of blood esmolol esterase . Drug Metab Dispos. 1985, 13:4204.

19. Melendez JA, Stone JG, Delphin E, Quon CY: Influence of temperature on in vitro metabolism of esmolol . J Cardiothorac Anesth. 1990, 4:704-6. 10.1016/s0888-6296(09)90007-2

20. Jacobs JR, Croughwell ND, Goodman DK, White WD, Reves JG: Effect of hypothermia and sampling site on blood esmolol concentrations. J Clin Pharmacol. 1993, 33:360-5. 10.1002/j.1552-4604.1993.tb04670.x

21. Sicari R, Nihoyannopoulos P, Evangelista A, et al.: Stress echocardiography expert consensus statement: 


\section{Cureus}

European Association of Echocardiography (EAE) (a registered branch of the ESC). Eur J Echocardiogr. 2008, 9:415-37. 10.1093/ejechocard/jen175

22. Krumpl G, Ulč I, Trebs M, Kadlecová P, Hodisch J: Pharmacodynamic and pharmacokinetic behavior of landiolol during dobutamine challenge in healthy adults. BMC Pharmacol Toxicol. 2020, 21:82. 10.1186/s40360-020-00462-X

23. Krumpl G, Ulč I, Trebs M, Kadlecová P, Hodisch J, Maurer G, Husch B: Pharmacodynamic and -kinetic behavior of low-, intermediate-, and high-dose landiolol during long-term infusion in whites. J Cardiovasc Pharmacol. 2017, 70:42-51. 10.1097/FJC.0000000000000495

24. Adamson PC, Rhodes LA, Saul JP, et al.: The pharmacokinetics of esmolol in pediatric subjects with supraventricular arrhythmias. Pediatr Cardiol. 2006, 27:420-7. 10.1007/s00246-006-1162-1

25. Turlapaty P, Laddu A, Murthy VS, Singh B, Lee R: Esmolol: a titratable short-acting intravenous beta blocker for acute critical care settings. Am Heart J. 1987, 114:866-85. 10.1016/0002-8703(87)90797-6

26. Tsunekawa K, Imakawa H, Yamamoto K, Shibakawa K, Hiraku S: Studies on the metabolic fate of ultra short acting $\beta 1$ blocker ONO-1101 (3): metabolism and protein binding. Yakobutsu Dotai (Drug Metab Pharmacokin). 1997, 12:31-41. 10.2133/DMPK.12.31

27. Ornstein E, Young WL, Ostapkovich N, Matteo RS, Diaz J: Are all effects of esmolol equally rapid in onset? Anesth Analg. 1995, 81:297-300. 10.1097/00000539-199508000-00015

28. Iizuka T, Kakinuma T, Hamada Y, Isshiki A: A novel ultra short acting beta-blocker, landiolol supress the central sympathetic nerve activity directory and exerts a more potent negative chronotropic effect and less effect on blood pressure than esmolol. Eur J Anesthesiol. 2004, 21:128.

29. Ornstein E, Young WL, Ostapkovich N, Matteo RS, Diaz J: Deliberate hypotension in patients with intracranial arteriovenous malformations: esmolol compared with isoflurane and sodium nitroprusside. Anesth Analg. 1991, 72:639-44. 10.1213/00000539-199105000-00012

30. Manasrah N, Naik R, Al Sbihi AF, Afonso LC: Coronary vasospasm after dobutamine stress echocardiogram triggered by esmolol. Cureus. 2020, 12:e10015. 10.7759/cureus.10015 